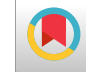

\title{
Renal Tubular Functions in Patients with Posterior Urethral Valve
}

\author{
Zeynep Alp Unkar (iD) ${ }^{1,}$, Nur Canpolat ${ }^{2}$, Mine Kucur $^{2}$, Salim Caliskan ${ }^{2}$ and Lale Sever ${ }^{2}$ \\ ${ }^{1}$ Beykoz Government Hospital, Istanbul, Turkey \\ ${ }^{2}$ Cerrahpasa School of Medicine, Istanbul, Turkey \\ "Corresponding author: Pediatrics, Beykoz Government Hospital, Beykoz Devlet Hastanesi, Yenidogan Yogun Bakim Unitesi, Pasabahce Mahallesi, Saip Molla Caddesi, Kisayol \\ Sokak, No: 1, Istanbul, Turkey. Tel: +90-5369876657, Email: md.zeynepalp@gmail.com
}

Received 2019 January 06; Revised 2019 February 12; Accepted 2019 February 27.

\begin{abstract}
Objectives: The aim of this study was to evaluate tubular functions of posterior urethral valve patients with preserved glomerular functions.

Methods: A total of 25 children (ages 1 - 18) who underwent surgery for PUV and had an estimated glomerular filtration rate $\geq$ $90 \mathrm{~mL} / \mathrm{min}$ per $1.73 \mathrm{~m}^{2}$ on long term follow-up and age-matched 25 healthy controls were enrolled. Blood and urine samples were collected to assess electrolyte reabsorption, proteinuria, enzymuria, urine acidification and concentration.

Results: Even though microalbumin/creatinine ratio was higher in the patient group [1.00 (1.98) vs 0.31 (0.34) mg/gr creatinine, P $=0.005]$ none of the subjects had enzymuria, overt proteinuria or hyperphosphaturia. Serum bicarbonate levels were lower and urinary $\mathrm{pH}$ higher in patients than the controls $(23.2 \pm 2.1 \mathrm{vs.} 24.6 \pm 1.9 \mathrm{mmol} / \mathrm{L}, \mathrm{P}=0.028$ and $6.24 \pm 0.77 \mathrm{vs} .5 .60 \pm 0.64, \mathrm{P}=0.004)$; furthermore, patients had lower urinary osmolality and density (525 \pm 214 vs. $743 \pm 194 \mathrm{mOsm} / \mathrm{L}, \mathrm{P}=0.001$ and $1011 \pm 5.0$ vs. 1016 $\pm 6.8, \mathrm{P}=0.005)$. When patients were compared among themselves according to presence or absence of renal scarring and when patients without renal scars were compared to healthy controls, similar findings persisted.

Conclusions: This study showed that during long-term follow-up of posterior urethral valve patients with normal glomerular filtration rates, even though proximal tubular functions do not seem to be impaired, acidification and concentration defects exist indicating distal tubulopathy.
\end{abstract}

Keywords: Posterior Urethral Valve, Renal Tubular Function, Proteinuria, Enzymuria

\section{Background}

In patients with posterior urethral valve (PUV), the prevalence of progression to end stage kidney disease (ESKD) is reported as $30 \%-42 \%(1,2)$. This degradation in renal function could be caused by many factors including primary renal dysplasia, secondary effects of the obstruction of urinary flow occurring in the early phases of nephrogenesis on fetal kidney, postnatal urinary tract infections (UTIs) and bladder dysfunction $(3,4)$. Most patients progressing to ESKD in the first year of life are those with renal dysplasia and those who were diagnosed in the early phases of gestation. Even though other patients' renal functions seem to be normal in the first year of life, an increasing number of patients were observed to progress to ESKD during follow-up period (5).

Patients treated for PUV are usually followed-up with serum levels of urea, creatinine and cystatin C, ultrasonography findings and bladder functions. Parameters of tubular function are often neglected.

\section{Objectives}

The aim of this study was to evaluate renal tubular in patients with PUV who underwent surgical intervention and are characterized by preserved glomerular function.

\section{Methods}

\subsection{Study Population}

For this cross-sectional single-center study, 60 patients with PUV who were treated by surgery and followedup in Istanbul University Cerrahpasa Faculty of Medicine were screened. Inclusion criteria were as follows: (i) patients aged between 1 and 18 years, (ii) patients who were followed-up for at least 6 months after the operation, (iii) patients who had an estimated glomerular filtration rate (GFR) greater than $90 \mathrm{~mL} / \mathrm{min}$ per $1.73 \mathrm{~m}^{2}$. Patients who had an active urinary tract infection at the time of study were excluded.

The demographic data of the study population, ages at the time of diagnosis and operation, and list of medications were recorded from the patients' files. 


\subsection{Radiologic and Nuclear Assessment}

Ultrasound (US) reports were reviewed and the presence of hydronephrosis or hydroureteronephrosis was recorded. Antero-posterior diameter (APD) of renal pelvis $>10 \mathrm{~mm}$ was defined as hydronephrosis. Existence of a ureter diameter of $\geq 4 \mathrm{~mm}$ was accepted as significant dilatation. The coexistence of vesicoureteral reflux (VUR) was noted from the cystometric assessments. Renal cortical damage or scarring was defined as focal parenchymal thinning or as a defect in renal contour or an area of photon deficiency on current dimercaptosuccinic acid (DMSA) scintigraphies.

\subsection{Laboratory Assessment}

Venous blood samples after an overnight fast were obtained from all patients and controls. Routine biochemical and blood gas parameters were examined in venous blood samples. Additionally, plasma was separated and stored at $-80^{\circ} \mathrm{C}$ for the measurement of cystatin-C. Plasma cystatinC concentrations ( $\mathrm{mg} / \mathrm{L}$ ) were measured by nephelometric method. Both updated Schwartz formula (5) and cystatin-C based equation (6) were used to estimate GFR.

First-morning urine samples were collected by midstream voiding, or by urethral catheters in patients who practice clean-intermittent catheterization. For non-toilet trained patients, a fresh bag urine specimen was used for urine tests. Urine samples were used for the measurements of routine urinalysis, $\mathrm{pH}$, specific gravity, osmolality, creatinine $(\mathrm{Cr})$, sodium $(\mathrm{Na})$, potassium $(\mathrm{K})$, calcium (Ca), phosphorus $(\mathrm{P})$, chloride $(\mathrm{Cl})$ and uric acid (UA). Ratio of calcium to creatinine $(\mathrm{Ca} / \mathrm{Cr})$ and uric acid to creatinine (UA/Cr), fractional Na excretion (FENa), transtubular potassium gradient (TTKG) and ratio of tubular maximum phosphate reabsorption to glomerular filtration rate (TmP/GFR) were calculated.

Urine specimens were also stored at $-80^{\circ} \mathrm{C}$ for the measurements of urinary microalbumin (MA), $\beta 2$ microglobulin $(\beta 2 \mathrm{M})$, retinol binding protein (RBP), $\mathrm{N}$-acetyl- $\beta$-D-glucosaminidase (NAG) and cystatin-C. Urinary MA was measured using auto analyzer. Urinary $\beta 2 \mathrm{M}$ and RBP concentrations were measured by nephelometric method and urinary NAG concentrations were analyzed by spectrophotometric method. All these urinary markers were assessed by their ratio to urinary creatinine concentration.

\subsection{Statistical Analysis}

SPSS 22.0 software for Windows was used for statistical analyses. Categorical variables were presented as a number (percentages) and the chi-square test was used to compare two categorical variables. Continuous data were expressed as mean \pm standard deviation (SD) or as median (interquartile range - IQR). Mann-Whitney U test was used for the comparisons of the continuous variables between the two groups. A P value $<0.05$ was considered indicative of statistical significance in all tests.

\section{Results}

Twenty-five patients with a median age of 5.5 (IQR: 8.5 ) years and a median follow-up period of 37(IQR: 64) months were ultimately enrolled in the study (patient group) and the control group consisted of 25 age-matched healthy boys. Fifteen patients (60\%) were antenatally diagnosed and operated at median age of 1.03 (2.0) months. For the postnatally diagnosed patients, median age at the time of surgery was 44.5 (IQR: 61.4) months. Seven patients were on prophylactic antibiotic therapy, 3 patients were receiving anti-cholinergic treatment and 5 patients were on both prophylaxis and anti-cholinergic therapy. Ten patients were not receiving any treatment.

Eleven (44\%) patients had bilateral and 5 (20\%) unilateral hydronephrosis/hydro-ureteronephrosis on the ultrasonographic examination. Nine (36\%) patients had VUR, ten $(40 \%)$ patients had renal scarring on DMSA scintigraphies and three (12\%) patients had single functional kidney.

\subsection{Laboratory Findings}

Serum biochemical parameters, except for level of serum bicarbonate $\left(\mathrm{HCO}_{3}\right)$ which was lower in the patient group ( $\mathrm{P}=0.028)$, did not differ between the patients and healthy controls (Table 1). Patients had significantly lower urinary density and osmolality, and higher urinary $\mathrm{pH}$ compared to healthy controls (Table 2). None of the patients or controls showed glucosuria or proteinuria in the dipstick test. Even though mean urinary MA/Cr level was significantly higher in patients than those in healthy controls $(\mathrm{P}=0.005)$, none of the patients showed microalbuminuria (30 - $300 \mathrm{mg} / \mathrm{g} \mathrm{Cr}$ ). Urinary NAG/Cr did not differ between the patient and control groups. While only one patient had a high level of urinary $\beta 2 \mathrm{M}(>7.25 \mathrm{mg} / \mathrm{L}$, normal value: $<0.23 \mathrm{mg} / \mathrm{L}$ ), none of the patients or controls showed increased level of urinary RBP.

Parameters of the patients with operated PUV who had normal DMSA scintigraphies and cortical irregularities were compared (Table 3). The three patients who had single functional kidney were excluded from this comparison. There was not any statistically significant difference between the results of the patients with and without renal cortical scarring. On the other hand, when the patients with normal renal cortical appearance were compared to healthy controls, the patients had significantly lower urinary density and osmolarity, and higher MA/Cr levels (Table 4). 


\begin{tabular}{|c|c|c|c|}
\hline & Healthy Controls & Patients with PUV & P Value \\
\hline Creatinine, $\mathrm{mg} / \mathrm{dL}$ & $0.48 \pm 0.13$ & $0.47 \pm 0.15$ & 0.39 \\
\hline $\mathrm{eGFR}^{\mathrm{a}}, \mathrm{mL} / \mathrm{min} / 1.73 \mathrm{~m}^{2}$ & $119 \pm 26$ & $109 \pm 19$ & 0.18 \\
\hline Cystatin-C, mg/L & $0.69 \pm 0.13$ & $0.74 \pm 0.23$ & 0.63 \\
\hline Sodium, mmol/L & $140 \pm 1.7$ & $139 \pm 2.3$ & 0.18 \\
\hline Potassium, mmol/L & $4.4 \pm 0.45$ & $4.5 \pm 0.60$ & 0.97 \\
\hline Chloride, mmol/L & $103 \pm 2.3$ & $103 \pm 2.4$ & 0.58 \\
\hline Calcium, $\mathbf{m m o l} / \mathbf{L}$ & $9.2 \pm 0.6$ & $9.4 \pm 0.4$ & 0.27 \\
\hline Phosphorus, mmol/L & $4.9 \pm 0.7$ & $4.7 \pm 0.7$ & 0.66 \\
\hline pH & $7.37 \pm 0.03$ & $7.37 \pm 0.06$ & 0.57 \\
\hline $\mathrm{HCO}_{3}, \mathrm{mmol} / \mathrm{L}$ & $24.6 \pm 1.9$ & $23.2 \pm 2.1$ & 0.028 \\
\hline Osmolality, mOsm/kg & $290 \pm 4.44$ & $288 \pm 7.08$ & 0.32 \\
\hline
\end{tabular}

a eGFR based on serum creatinine.

b eGFR based on serum cystatin-C.

\begin{tabular}{|c|c|c|c|}
\hline & Healthy Controls & Patients with PUV & P Value \\
\hline Density & $1016 \pm 6.9$ & $1011 \pm 5.0$ & 0.005 \\
\hline $\begin{array}{l}\text { Osmolality, } \\
\text { mOsm/L }\end{array}$ & $743 \pm 194$ & $525 \pm 214$ & 0.001 \\
\hline $\mathbf{p H}$ & $5.60 \pm 0.65$ & $6.24 \pm 0.77$ & 0.004 \\
\hline FENa, $\%^{\mathrm{a}}$ & $0.60(0.74)$ & $0.58(0.49)$ & 0.76 \\
\hline TTKG $^{\mathbf{a}}$ & $6.64(4.4)$ & $5.87(4.4)$ & 0.59 \\
\hline $\mathrm{Ca} / \mathrm{Cr}, \mathrm{mg} / \mathrm{mg}^{\mathrm{a}}$ & $0.05(0.08)$ & $0.06(0.09)$ & 0.98 \\
\hline TmP/GFR & $4.63 \pm 0.71$ & $4.29 \pm 0.63$ & 0.16 \\
\hline Uricasid/GFR & $0.26 \pm 0.08$ & $0.30 \pm 0.10$ & 0.16 \\
\hline $\mathrm{NAG} / \mathrm{Cr}, \mathrm{U} / \mathbf{m g}^{\mathbf{a}}$ & $0.23(0.22)$ & $0.27(0.26)$ & 0.48 \\
\hline $\mathrm{MA} / \mathrm{Cr}, \mathrm{mg} / \mathrm{gr} \mathrm{Cr}^{\mathrm{a}}$ & $0.31(0.34)$ & $1.00(1.98)$ & 0.005 \\
\hline \multicolumn{4}{|c|}{$\begin{array}{l}\text { Abbreviations: FENa, fractional Na excretion; MA, microalbumin; NAG, N- } \\
\text { acetyl- } \beta \text {-D-glucosaminidase; TmP, tubular maximum phosphate reabsorption; } \\
\text { TTKG, trans-tubular potassium gradient. }\end{array}$} \\
\hline
\end{tabular}

\section{Discussion}

In this study conducted with operated PUV disease patients whose eGFRs were greater than $90 \mathrm{~mL} / \mathrm{min}$ per $1.73 \mathrm{~m}^{2}$, we found that serum $\mathrm{HCO}_{3}$, urinary $\mathrm{pH}$, osmolality, density and $\mathrm{MA} / \mathrm{Cr}$ ratios were significantly different among study and control groups. Other tests, especially those for tubular proteinuria, were inconclusive.

Regarding the fact that distal tubule, whose main functions are concentration and acidification of urine $(7,8)$, is the first "front" facing the insult of retrograde urinary flow in the intrauterine period, it would be logical to state that this part would also be the first and most affected structure in a nephron in PUV disease $(4,9,10)$. Consistent with this statement, our study group's mean urinary $\mathrm{pH}$ was lower, and mean density and osmolality values were higher than the means of the control group. Even though these patients do not seem to be in the process of ESKD, these results show that on cellular level a functional deterioration has begun in the distal part pf the nephron; which, in the future, might progress proximally causing general degradation in renal function.

Distal renal tubular acidosis (dRTA) in patients with ablated PUVs has been researched in detail by Sharma et al (11-13). Their researches encompass all the patients who underwent surgery for PUV, disregarding their GFRs; and their follow-up duration after the surgery was shorter than that of our patients.

There have been studies inquiring for proteinuria in PUV patients $(14,15)$; however, in these studies majority of the patients either had ESKD or elevated $\mathrm{Cr}$ and cystatin-C levels depicting a decrease in GFRs and therefore rendering it infeasible to name the source of proteinuria as glomerular or tubular. In our study, even though MA/Cr ratios were within normal reference range (16) in all cases, the difference between study and control groups was statistically significant, the former's ratio being higher. Considering that reabsorption of albumin from the glomerular filtrate is a function of the proximal tubule (17), while there were not any patients in our study group whose urine MA/Cr ratios were within microalbuminuria range, the significant increase in this ratio in the study group may be an early indicator of proximal tubular dysfunction in PUV patients with normal glomerular function. 


\begin{tabular}{|c|c|c|c|}
\hline & Healthy Controls & Normal Scintigraphy & P Value \\
\hline Creatinine, mg/dL & $0.48 \pm 0.13$ & $0.48 \pm 0.17$ & 0.53 \\
\hline $\mathrm{eGFR}^{\mathrm{a}}, \mathrm{mL} / \mathrm{min} / 1.73 \mathrm{~m}^{2}$ & $119 \pm 26$ & $111 \pm 21$ & 0.41 \\
\hline Cystatin-C, mg/L & $0.69 \pm 0.13$ & $0.74 \pm 0.23$ & 0.64 \\
\hline $\mathrm{eGFR}^{\mathrm{b}}, \mathrm{mL} / \mathrm{min} / 1.73 \mathrm{~m}^{2}$ & $103 \pm 21$ & $102 \pm 32$ & 0.64 \\
\hline Sodium, mmol/L & $140 \pm 1.7$ & $139 \pm 1.48$ & 0.15 \\
\hline Potassium, mmol/L & $4.4 \pm 0.45$ & $4.51 \pm 0.37$ & 0.60 \\
\hline Chloride, $\mathbf{m m o l} / \mathbf{L}$ & $103 \pm 2.3$ & $102 \pm 1.71$ & 0.15 \\
\hline Calcium, mmol/L & $9.2 \pm 0.6$ & $9.4 \pm 0.4$ & 0.53 \\
\hline Phosphorus, mmol/L & $4.9 \pm 0.7$ & $5.0 \pm 0.8$ & 0.41 \\
\hline pH & $7.37 \pm 0.03$ & $7.38 \pm 0.24$ & 0.41 \\
\hline $\mathrm{HCO}_{3}, \mathrm{mmol} / \mathrm{L}$ & $24.6 \pm 1.9$ & $23.6 \pm 2.1$ & 0.14 \\
\hline Osmolality, mOsm/kg & $290 \pm 4.44$ & $288 \pm 4.44$ & 0.31 \\
\hline
\end{tabular}

a eGFR based on serum creatinine.

b eGFR based on serum cystatin-C.

Table 4. Urinary Findings of Controls Versus Patients with Normal DMSA Scintigraphy

\begin{tabular}{lccc}
\hline & Healthy Controls & $\begin{array}{c}\text { Normal } \\
\text { Scintigraphy }\end{array}$ & PValue \\
\hline Density & $1016 \pm 6.9$ & $1011 \pm 4.8$ & 0.038 \\
\hline $\begin{array}{l}\text { Osmolality, } \\
\text { mOsm/L }\end{array}$ & $743 \pm 194$ & $548 \pm 229$ & 0.010 \\
\hline pH & $5.60 \pm 0.65$ & $6.09 \pm 0.90$ & 0.14 \\
\hline FENa, \% & $0.60(0.74)^{\mathrm{a}}$ & $0.67 \pm 0.11$ & 0.99 \\
\hline TTKG & $6.64(4.4)^{\mathrm{a}}$ & $6.68 \pm 2.89$ & 0.99 \\
\hline Ca/Cr, mg/mg & $0.05(0.08)$ & $0.07(0.10)$ & 0.79 \\
\hline TmP/GFR & $4.63 \pm 0.71$ & $4.50 \pm 0.63$ & 0.89 \\
\hline Uricasid/GFR & $0.26 \pm 0.08$ & $0.32 \pm 0.09$ & 0.12 \\
\hline NAG/Cr, U/mg & $0.23(0.22)$ & $0.29(0.47)$ & 0.38 \\
\hline MA/Cr, mg/gr Cr & $0.31(0.34)$ & $1.11(1.98)$ & 0.004 \\
\hline
\end{tabular}

Abbreviations: FENa, fractional Na excretion; MA, microalbumin; NAG, Nacetyl- $\beta$-D-glucosaminidase; TmP, tubular maximum phosphate reabsorption; TTKG, trans-tubular potassium gradient.

${ }^{a}$ Values are expressed as median (IQR).

In our study, proteinuria was also assessed by urinary $\mathrm{RBP}, \beta 2 \mathrm{M}$ levels and NAG/Cr ratio. The results for all three parameters were within the normal range and there were no statistically significant differences among patient and healthy groups. There are no studies in literature evaluating these parameters of PUV patients in postnatal period; however, there are studies showing increased urinary excretion of $\beta 2 \mathrm{M}$ and NAG in other obstructive uropathies, especially ureteropelvic junction obstructions $(18,19)$.

Comparisons within the patient group itself (scar ver- sus no scar on DMSA scintigraphy), and patients without cortical scar versus healthy controls were done to inquire whether visible renal parenchymal damage was associated with tubular functions or not. The findings suggest that, although renal cortical imaging is normal, functional tubular disorders persist even after a long period of time has passed since valve ablation in patients with PUV.

The strength of our study is that it encompasses a very specific group of patients with preserved glomerular function who are not in the process of progression to ESKD. Even though glomerular function was normal, test results were significant for distal tubulopathy, providing a clearer vision for the follow-up of these patients. Moreover, according to comparisons between control group, and patients with cortical scars and those without scars, it was demonstrated that cortical scarring cannot predict the degradation of tubular function. The greatest limitation of our study was the low number of patients. Even though the initial number of our patients was 60, in the end only 25 were eligible for the study. Researches with larger groups of patients are necessary for more accurate results. Another limitation is that our research was designed as a cross-sectional and observational study, disallowing any intervention. Therefore, even though ammonium chloride load test would have allowed us to distinguish complete and incomplete dRTA cases (20), it was not undertaken. As for proximal tubulopathy, except for $\mathrm{MA} / \mathrm{Cr}$ ratio tests for proximal tubule function were inconclusive. The statistically significant difference between the study and control groups would, by itself, be inadequate to prove the presence of proximal tubulopathy as it was not supported by increased urinary excretion of RBP or $\beta 2 \mathrm{M}$. With 
larger study and control groups, these tests could yield more conclusive results.

In conclusion, our study shows that degradation in glomerular function (tests used more commonly during follow-up) or renal scarring are not necessary for the development of tubulopathies. Even if the data acquired is inadequate to confirm the presence of proximal tubulopathy, the development of distal tubulopathy is evident. Longterm evaluation of the same study group may result in several patients' progression to ESKD; therefore, providing parameters to predict disease progress. Even though MA levels were within normal range in both groups, $\mathrm{MA} / \mathrm{Cr}$ ratio was the only significantly different parameter in our study which might be indicating the beginning of proximal tubular damage, making this ratio a promising parameter to pursue in the studies to come.

\section{Footnotes}

Authors' Contribution: Zeynep Alp Unkar and Lale Sever designed the study; Zeynep Alp Unkar collected the samples and performed laboratory studies together with Mine Kucur; Zeynep Alp Unkar and Nur Canpolat collected and analysed data; Zeynep Alp Unkar, Nur Canpolat and Lale Sever wrote the manuscript; Lale Sever and Salim Caliskan gave technical support and conceptual advice. All authors read and approved the final manuscript.

Conflict of Interests: The authors disclose no conflict of interests.

Ethical Approval: The study protocol was approved by the Ethical Committee of Istanbul University, Cerrahpasa Faculty of Medicine (date of approval: May 9th, 2011; number: 16372).

Funding/Support: This work was supported by Scientific Research Projects Coordination Unit of Istanbul University (project number: 17929).

Patient Consent: Informed consent was obtained from the parents of all children.

\section{References}

1. Cainone P, Innocenzi M. Posterior urethral valves. In: Puri P, editor Newborn surgery. 4th ed. Florida: CRC Press Taylor \& Francis Group; 2018.

2. Elder JS. Obstruction of the urinary tract. In: Kliegman RM, Stanton BF, Geme JW, Schor NF, editors. Nelson textbook of pediatrics. 20th ed. Philadelphia: Elsevier; 2016. p. 2567-75.

3. Sudarsanan B, Nasir AA, Puzhankara R, Kedari PM, Unnithan GR, Damisetti KR. Posterior urethral valves: A single center experience over 7 years. Pediatr Surg Int. 2009;25(3):283-7. doi: 10.1007/s00383009-2332-z. [PubMed: 19184051].

4. Kajbafzadeh A. Congenital urethral anomalies in boys. Part I: posterior urethral valves. Urol J. 2005;2(2):59-78. [PubMed: 17629874].
5. Schwartz GJ, Munoz A, Schneider MF, Mak RH, Kaskel F, Warady BA, et al. New equations to estimate GFR in children with CKD. J Am Soc Nephrol. 2009;20(3):629-37. doi: 10.1681/ASN.2008030287. [PubMed: 19158356]. [PubMed Central: PMC2653687].

6. Grubb A. Non-invasive estimation of glomerular filtration rate (GFR). The Lund model: Simultaneous use of cystatin C- and creatinine-based GFR-prediction equations, clinical data and an internal quality check. Scand J Clin Lab Invest. 2010;70(2):65-70. doi: 10.3109/00365511003642535. [PubMed: 20170415]. [PubMed Central: PMC4673578].

7. Bagga A, Bajpai A, Menon S. Approach to renal tubular disorders. Indian J Pediatr. 2005;72(9):771-6. doi: 10.1007/BF02734150. [PubMed: 16186680].

8. Skinner R, Pearson AD, Coulthard MG, Skillen AW, Hodson AW, Goldfinch ME, et al. Assessment of chemotherapy-associated nephrotoxicity in children with cancer. Cancer Chemother Pharmacol. 1991;28(2):81-92. doi: 10.1007/BF00689694. [PubMed: 2060086].

9. Caione P, Nappo S. Posterior urethral valves. In: Puri PMH, editor. Pediatric surgery. Heidelberg: Springer; 2009. p. 863-79. doi:10.1007/9783-540-69560-8_88.

10. Dinneen MD, Duffy PG, Barratt TM, Ransley PG. Persistent polyuria after posterior urethral valves. Br J Urol. 1995;75(2):236-40. doi: 10.1111/j.1464-410X.1995.tb07318.x. [PubMed: 7850332].

11. Sharma AP, Sharma RK, Kapoor R, Kornecki A, Sural S, Filler G. Incomplete distal renal tubular acidosis affects growth in children. Nephrol Dial Transplant. 2007;22(10):2879-85. doi:10.1093/ndt/gfm307. [PubMed: 17556420].

12. Sharma RK, Sharma AP, Kapoor R, Gupta A. Prognostic significance of distal renal tubular acidosis in posterior urethral valve. Pediatr Nephrol. 2001;16(7):581-5. doi: 10.1007/s004670100590. [PubMed: 11465808].

13. Sharma RK, Sharma AP, Kapoor R, Pandey CM, Gupta A. Prognostic factors for persistent distal renal tubular acidosis after surgery for posterior urethral valve. Am J Kidney Dis. 2001;38(3):488-93. doi: 10.1053/ajkd.2001.26832. [PubMed: 11532679].

14. Miklovicova D, Cervenova O, Cernianska A, Jancovicova Z, Dedik L, Vasilenkova A. Long-term follow-up of renal function in patients after surgery for obstructive uropathy. Pediatr Nephrol. 2008;23(6):937-45. doi: 10.1007/s00467-007-0741-6. [PubMed: 18286308].

15. Roth KS, Carter WH Jr, Chan JC. Obstructive nephropathy in children: Long-term progression after relief of posterior urethral valve. Pediatrics. 2001;107(5):1004-10. doi:10.1542/peds.107.5.1004. [PubMed: 11331678].

16. Toto RD. Microalbuminuria: definition, detection, and clinical significance. J Clin Hypertens (Greenwich). 2004;6(11 Suppl 3):2-7. doi: 10.1111/j.1524-6175.2004.4064.x. [PubMed: 15538104].

17. Dickson LE, Wagner MC, Sandoval RM, Molitoris BA. The proximal tubule and albuminuria: Really!. J Am Soc Nephrol. 2014;25(3):443-53. doi: 10.1681/ASN.2013090950. [PubMed: 24408874]. [PubMed Central: PMC3935594]

18. Bartoli F, Penza R, Aceto G, Niglio F, D'Addato O, Pastore V, et al. Urinary epidermal growth factor, monocyte chemotactic protein-1, and beta2microglobulin in children with ureteropelvic junction obstruction. J Pediatr Surg. 2011;46(3):530-6. doi: 10.1016/j.jpedsurg.2010.07.057. [PubMed: 21376205].

19. Carr MC, Peters CA, Retik AB, Mandell J. Urinary levels of the renal tubular enzyme N-acetyl-beta-D-glucosaminidase in unilateral obstructive uropathy. J Urol. 1994;151(2):442-5. doi: 10.1016/S00225347(17)34983-2. [PubMed: 8283554].

20. Lascelles PT, Donaldson D. Ammonium chloride load test. In: Lascelles PT, Donaldson D, editors. Diagnostic function tests in chemical pathology. Dordrecht: Springer; 1989. p. 3-4. doi: 10.1007/978-94-0091846-7_2. 